\title{
Hipertermia Maligna Anestésica
}

\section{Anesthetic Malignant Hyperthemia}

\section{José Luiz Gomes do Amaral}

Professor Titular, Disciplina de Anestesiologia, Dor e Terapia Intensiva Cirúrgica, Escola Paulista de Medicina I Universidade Federal de São Paulo - UNIFESP.

\section{Definição}

A hipertermia maligna (HM) é afecção hereditária e latente, caracterizada por resposta hipermetabólica aos anestésicos voláteis (halotano, enflurano, isoflurano, sevoflurano $e$ desflurano) e, provavelmente, succinilcolina.

\section{Etiologia}

A HM humana é de herança autossômica dominante. Ela está associada a mais de um gene, nem todos os susceptíveis compartilhando do mesmo padrão genético.

\section{Fisiopatologia}

Em condições normais, os níveis de $\mathrm{Ca}^{++}$no mioplasma são controlados pelo receptor rianodina do retículo sarcoplasmático, o receptor dihidropiridina do túbulo transverso e pelo sistema $\mathrm{Ca}^{++}$-adenosina trifosfatase $\left(\mathrm{Ca}^{++}\right.$-ATPase). Na crise de $\mathrm{HM}$, em função de desarranjo da homeostase intracelular do $\mathrm{Ca}^{++}$, é desencadeada hiperatividade contrátil, hidrólise do ATP, hipertermia, aumento do consumo de $\mathrm{O}_{2}$, produção de $\mathrm{CO}_{2}$ e ácido lático, desacoplamento da fosforilação oxidativa, lise celular e extravasamento do conteúdo do citoplasma.

\section{Incidência}

Em geral, a HM incide a cada 50000 anestesias. Em virtude da exposição aos agentes desencadeantes (prática clínica) e da natureza genética da síndrome, a incidência de HM varia nas diferentes populações estudadas. Ocorre em indivíduos das raças branca e amarela. A susceptibilidade ocorre igualmente em ambos os sexos, ainda que as crises sejam mais comuns em homens. Episódios de HM são freqüentes em crianças (1/10000 anestesias), e raros em idosos. 


\section{Quadro clínico}

A expressão clínica da HM é variável. Ela surge a qualquer momento durante a anestesia e até 3 horas após a interrupção da exposição ao agente desencadeante.

Esta condição é expressa por rigidez muscular, aumento do consumo de oxigênio e produção de $\mathrm{CO}_{2}$, acidemia (respiratória e metabólica), taquicardia, taquipnéia, hiperpotassemia, rabdomiólise e mioglobinúria. Nem sempre hipertermia é manifestação inicial ou proeminente da HM.

\begin{tabular}{|c|c|}
\hline \multicolumn{2}{|c|}{$\begin{array}{l}\text { Hipertermia Maligna. } \\
\text { Manifestaçôes clinicas iniciaris. }\end{array}$} \\
\hline Taquicardia & $96,0 \%$ \\
\hline Rigidez muscular & $83,6 \%$ \\
\hline Instabilidade hemodinâmica & $85,5 \%$ \\
\hline Taquipnéia & $85,0 \%$ \\
\hline Cianose & $71,1 \%$ \\
\hline Hipertermia & $30,0 \%$ \\
\hline
\end{tabular}

\section{Diagnóstico}

\section{$\underline{\text { Crise de HM }}$}

Nas crises, o diagnóstico de HM é fundamentado no quadro clínico. Os exames complementares têm maior utilidade na avaliação das complicações e da resposta ao tratamento.

\begin{tabular}{|c|}
\hline Hiperternia Maligna. \\
Características fundannentais. \\
\hline Resposta hipermetabólica a anestésicos voláteis ou succinilcolina. \\
Destruição muscular. \\
Hereditariedade. \\
\hline
\end{tabular}

A capnografia tem grande valor no diagnóstico precoce da HM e na avaliação da resposta ao tratamento. Aumento da concentração de $\mathrm{CO}_{2}$ no gás expirado $\left(\mathrm{EtCO}_{2}\right)$ acima de 5 $\mathrm{mmHg}$ merece investigação. De fato, elevações acentuadas do $\mathrm{E} \mathrm{CO}_{2}$, da concentração de $\mathrm{CO}_{2}$ no sangue venoso $\left(\mathrm{PvCO}_{2}\right)$, sangue arterial $\left(\mathrm{PaCO}_{2}\right)$ e diferença veno-arterial de $\mathrm{CO}_{2}$ são observadas precocemente nos casos fulminantes, mas podem ser atenuadas por hiperventilação nas crises moderadas. 
Destacam-se ainda aumentos da potassemia, CPK (12 a 24 horas após o início da crise), creatininemia e distúrbios da hemostasia. Algumas crises de HM podem ser acompanhadas de elevação dos níveis de CPK acima de 20000 UI/L. Todavia, na maioria dos casos, os valores de CPK não excedem este limiar. O tratamento com dantrolene não parece afetar a elevação da CPK plasmática. Em cerca de 30\% das crises de HM tratadas com dantrolene, os picos de CPK encontram-se dentro dos níveis associados à maioria dos procedimentos cirúrgicos. A succinilcolina está relacionada a valores mais expressivos de CPK. Quando ela não é usada, em 50\% dos pacientes com HM, os níveis de CPK permanecem dentro do esperado para uma operação não complicada por HM.

\section{Biópsia muscular}

Teste halotano-cafeína (CHCT: cafeine halothane contracture test). Fora da crise, a susceptibilidade é confirmada pela resposta de músculo isolado (espécime de biópsia) a concentrações crescentes de halotano e cafeína (sensibilidade próxima a 100\%, falso-positivos entre 10 e $20 \%$ ).

A biópsia muscular para realização do CHCT é realizada distante das crises (o músculo agudamente afetado pode ser irresponsivo) e requer hospitalização (intervenção cirúrgica, anestesia e observação).

\section{Diagnóstico diferencial}

As manifestações clínicas e laboratoriais da HM são inespecíficas e ocorrem em incidência variável. Taquicardia, taquipnéia, hipercarbia, acidose respiratória, acidose metabólica, rigidez de masseter, rigidez muscular generalizada, mioglobinúria, rabdomiólise, arritmias, cianose, má perfusão cutânea, hiperpotassemia, diaforese, elevação da temperatura, instabilidade hemodinâmica e alterações da coagulação confundem-se com diversas situações clínicas (KAPLAN, 1991)

Além da $\mathrm{HM}$, diversas situações resultam em elevação da $\mathrm{E} t \mathrm{CO}_{2}$ : aumento da produção de $\mathrm{CO}_{2}$ (outras causas de hipermetabolismo e febre), hipoventilação (depressão respiratória por anestesia profunda em ventilação espontânea, disfunção do ventilador ou válvulas unidirecionais, vazamentos ou obstrução no circuito de ventilação, balonete do tubo traqueal não insuflado, intubação endobrônquica acidental, broncoespasmo, secreções ou sangue obstruindo a árvore respiratória, edema pulmonar, redução da expansão pulmonar por diminuição da complacência pulmonar, coleções pleurais gasosas ou líquidas, aumento do 
tono muscular do abdomen ou compressão por afastadores). Ao longo das intervenções

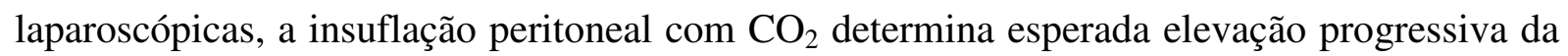
$\mathrm{EtCO}_{2}$.

A elevação da temperatura pode também resultar de calor ambiente (sistemas de aquecimento mal ajustados), hipermetabolismo (tireotoxicose, feocromocitoma, osteogênese imperfecta, infecção, reação pirogênica, lesão hipotalâmica; reação a drogas, como anfetaminas, inibidores da monoamino oxidase, atropina, glicopirrolato, cocaína, anfetamina, droperidol, metoclopramida, cetamina; síndrome neuroléptica maligna e interrupção do uso de levodopa).

A definição clínica imprecisa de $\mathrm{HM}$ dificulta a estimativa de risco de susceptibilidade (probabilidade de a exposição de determinado indivíduo a agente anestésico desencadeante venha a provocar um crise de HM). O problema torna-se ainda mais complexo, se considerado que nem todo o susceptível desenvolve HM quando exposto e que a penetrância do gene é variável.

A partir da opinião de experts em HM foi construída uma Escala Clínica Graduada (CGS-MH) de probabilidade qualitativa (variando da quase impossibilidade à certeza) de que uma reação adversa sob anestesia corresponda a uma crise de HM, ou que determinado paciente seja susceptível. Na CGS-HM são considerados fatores relativos a processos fisiopatológicos distintos. Em cada processo fisiopatológico é considerado APENAS o fator de maior peso (ou pontuação).

A aplicação da CGS-HM não prescinde de diagnóstico diferencial. Nesta escala, o julgamento clínico é fundamental para discernir alterações compatíveis com as condições clínicas, técnica de anestesia ou intervenção cirúrgica daquelas inapropriadas, consideradas então atribuíveis à HM.

A classificação na CGS-HM não se destina a orientar conduta clínica frente a um caso de HM: mesmo pontuações baixas podem ser obtidas de episódios frustros de HM e de indivíduos realmente susceptíveis. Isto é particularmente verdadeiro quando a investigação clínica e laboratorial é incompleta ou quando faltam antecedentes pessoais e familiares. A maior aplicação da CGS-HM é a estratificação de populações em investigações clínicas. 
Indicadores de Hipertermia Maligna.

\begin{tabular}{|l|l|c|}
\hline \multicolumn{1}{|c|}{ Processo } & \multicolumn{1}{|c|}{ Indicador } & Pontos \\
\hline Rigidez & Generalizada (exceto shivering) & $15 \mathrm{ou}$ \\
& Espasmo de masseter após succinilcolina & 15 \\
\hline Destruição muscular & CPK>20 000 UI com Succinilcolina & $15 \mathrm{ou}$ \\
& CPK>10 000 UI sem Succinilcolina & $15 \mathrm{ou}$ \\
& Urina cor de Coca-Cola & $10 \mathrm{ou}$ \\
& Mioglobinúria $>60 \mathrm{mcg} / 1$ & $5 \mathrm{ou}$ \\
& Mioglobinemia $>170 \mathrm{mcg} / 1$ & $5 \mathrm{ou}$ \\
& Potassemia $>6 \mathrm{mEq} / 1$ & 3 \\
\hline Acidose respiratória & PETCO2>50 mmHg em Ventilação controlada & $15 \mathrm{ou}$ \\
& PaCO2>60 mmHg em Ventilação controlada & $15 \mathrm{ou}$ \\
& PETCO2>65 mmHg em Ventilação espontânea & $15 \mathrm{ou}$ \\
& PaCO2>60 mmHg em Ventilação espontânea & $15 \mathrm{ou}$ \\
& Hipercarbia (inapropriada) & $15 \mathrm{ou}$ \\
& Taquipnéia (inapropriada) & 10 \\
\hline Acidose metabólica & BEa além de -8 mEq/l & 10 \\
\hline Acidemia & pHa $<7,25$ & 10 \\
\hline Hipertermia & Elevação rápida da T (inapropriada) & $15 \mathrm{ou}$ \\
& T> 38,8 ${ }^{\circ}$ C (inapropriada) & 10 \\
\hline Ritmo cardíaco & Taquicardia sinusal (inapropriada) & $3 \mathrm{ou}$ \\
& Taquicardia ou fibrilação ventricular & 5 \\
\hline Dantrolene \& acidose & Reversão rápida (respiratória ou metabólica) & 5 \\
\hline
\end{tabular}

Susceptibilidade à hipertermia maligna.

\begin{tabular}{|l|c|}
\hline \multicolumn{1}{|c|}{ Indicadores } & Pontos \\
\hline Antecedente em familiar de primeiro grau & $15 \mathrm{ou}$ \\
Antecedente em familiar outro que não de primeiro grau & 5 \\
\hline Antecedente em familiar \& pessoal, exceto CK elevada em repouso & 10 \\
\hline CK elevada em repouso & 10 \\
\hline
\end{tabular}

Estimativa de probabilidade.

NÃO somar pontos de indicadores de um mesmo processo. Considerar a pontuação máxima de cada processo.

\begin{tabular}{|c|c|l|}
\hline Pontuação & Risco de HM & Probabilidade \\
\hline 0 & 1 & Quase impossível \\
\hline a 9 & 2 & Improvável \\
\hline 10 a 19 & 3 & Algo menos que provável \\
\hline 20 a 34 & 4 & Algo mais que provável \\
\hline 35 a 49 & 5 & Bastante provável \\
\hline 50 ou + & 6 & Quase certo \\
\hline
\end{tabular}




\section{Complicações}

As principais complicações da HM vêm a ser hipertensão arterial (fase inicial), colapso circulatório (choque), arritmias cardíacas, distúrbios da hemostasia (coagulação intravascular disseminada), insuficiência renal aguda. Freqüentes e eventualmente fulminantes, tais complicações contribuem para a gravidade da HM.

\section{Tratamento}

\section{Fase aguda}

1. Interrupção imediata da inalação de anestésicos voláteis e/ou succinilcolina.

2. Hiperventilação com oxigênio puro (não há necessidade de troca do circuito circular ou sistema de absorção de $\mathrm{CO}_{2}$ ).

3. Dantrolene sódico: Injeções intravenosas de $2,5 \mathrm{mg} / \mathrm{kg}$, repetidas até o completo controle das manifestações de HM. Ainda que doses maiores sejam eventualmente necessárias, o controle das crise de HM é obtido na maioria dos casos com dose total inferior a $10 \mathrm{mg} / \mathrm{kg}$.

Diluir cada frasco-ampola, contendo $20 \mathrm{mg}$ de dantrolene e $3 \mathrm{~g}$ de manitol, em $60 \mathrm{ml}$ de ÁGUA estéril.

4. Bicarbonato de sódio intravenoso, conforme o bicarbonato sérico (em geral, 1 a $2 \mathrm{mEq} / \mathrm{kg}$ ); 5. Resfriamento ativo: Lavagem gástrica, vesical, retal e cavidades (peritoneal ou torácica) eventualmente abertas com $\mathrm{NaCl}$ 0,9\% gelado; colchão hipotérmico e aplicação de gelo na superfície corporal. Evitar hipotermia, interrompendo o resfriamento com temperaturas inferiores a $38^{\circ} \mathrm{C}$.

6. Tratamento das arritmias cardíacas (geralmente controladas com o tratamento da hiperpotassemia e acidemia). Entre os antiarrítmicos, não usar bloqueadores de canais de $\mathrm{Ca}^{++}$, associados a hiperpotassemia e colapso circulatório.

7. Tratamento da hiperpotassemia, com hiperventilação, bicarbonato de sódio, Solução "polarizante" ( $0,15 \mathrm{U}$ de insulina simples/kg em $1 \mathrm{ml} / \mathrm{kg}$ de glicose $50 \%)$, cloreto de $\mathrm{Ca}^{++}$ intravenoso - 2 a $5 \mathrm{mg} / \mathrm{kg}$ (arritmias graves).

8. Manter diurese acima de $2 \mathrm{ml} / \mathrm{kg} / \mathrm{hora}$ : Hidratação, manitol ou furosemida.

\section{Fase tardia}

1. Face ao risco de recidiva é conveniente observação em Unidade de Tratamento Intensivo durante pelo menos 24 horas. 
2. Dantrolene intravenoso $1 \mathrm{mg} / \mathrm{kg}$ a cada 6 horas, durante 48 horas.

3. Controles a cada 6 horas: temperatura, gasometria arterial, níveis sangüíneos de creatinofosfocinase (CPK), potássio e $\mathrm{Ca}^{++}$, coagulograma, mioglobina sérica e urinária.

4. Orientação do paciente e familiares acerca da doença.

\section{Prevenção (cuidados com susceptíveis confirmados ou potenciais)}

1. Quando possível, considerar confirmação diagnóstica (biópsia muscular) dos casos suspeitos de HM e de rigidez de masseter.

2. Evitar exposição a agentes desencadeantes. Resíduos de anestésicos voláteis podem desencadear crise de HM: recomenda-se evitar circuito de ventilação previamente usado para administração de halogenados;

3. Monitorização da temperatura central e capnografia;

4. Garantir disponibilidade imediata (na sala de operação) de tratamento específico (dantrolene sódico);

5. Observação em postanestésico durante pelo menos 3 horas.

Dada a improbabilidade de episódios graves de HM sem prévia exposição a agentes desencadeantes e o dantrolene não seja completamente isento de efeitos colaterais, sua administração profilática não é recomendada.

\section{Prognóstico}

A HM, já foi associada a mortalidade acima de 70\%. Diagnóstico precoce e rápida instituição de tratamento específico fazem possível reduzi-las a menos de $10 \%$.

Relação entre o prognóstico e tempo desde a exposição ao agente desencadeante e o início do tratamento com dantrolene.

\begin{tabular}{|c|c|c|}
\hline Tempo decorrido da indução (minutos) & Mortes & Sobreviventes \\
\hline $0-29$ & 0 & 9 \\
\hline $30-59$ & 0 & 7 \\
\hline $60-119$ & 0 & 12 \\
\hline $120-179$ & 2 & 4 \\
\hline$>180$ & 8 & 7 \\
\hline
\end{tabular}


Para obter informações sobre o tratamento de episódios agudos consulte:

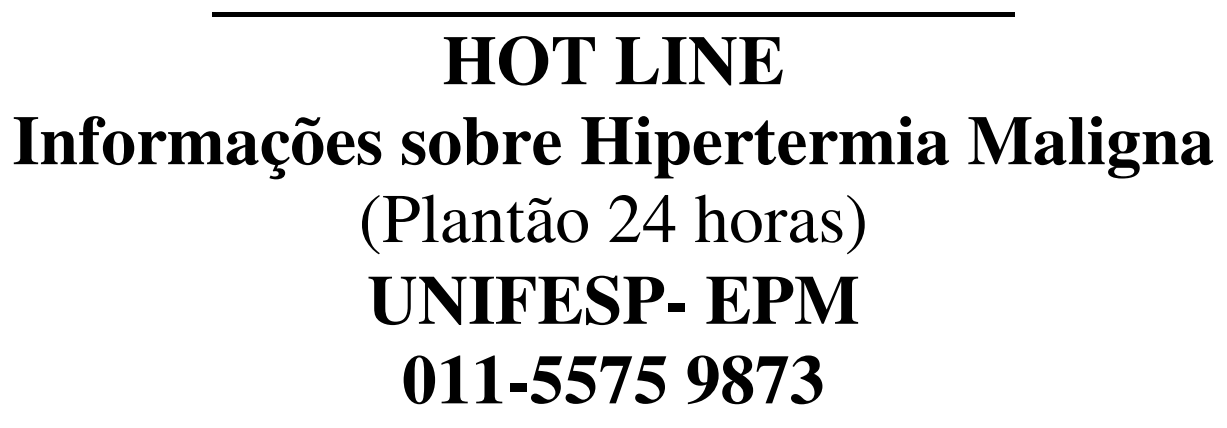

\section{Referência}

1. Amaral JLG, Carvalho RB. Hipertermia maligna. In: Anestesiologia: Princípios e Técnicas. J Manica e col. (Eds.). $3^{\text {a }}$. edição, Rio de Janeiro: ArtMed, 2004, 1207-1224. 